\title{
Analysis on the Design of Tourism Customer Relationship Management under the Environment of E-commerce
}

\author{
Ding Chen \\ E-commerec College of Business Xi'an International University, Shaanxi China, 710071
}

Keywords: e-commerce, travel customer relationship management, value chain, value promotion

Abstract: Since the beginning of the 21 st century, the business philosophy of enterprises has changed from product-centered to tourism-oriented customers. Therefore, strengthening tourism customer relationship management has become more and more important. Effective travel CRM activities are a practice that is not limited to products and services. This paper reviews the related connotation of tourism customer service in detail, discusses the tourism customer value theory in the e-commerce environment, and gives the ways to improve the management value of tourism customers in the e-commerce environment from two perspectives.

\section{Introduction}

Manager Dr. Drucker once said that the essence of business management is to acquire and retain customers; only consumers are the only source of wealth for enterprises. After more than one hundred years of development, modern enterprise management theory has evolved from "product-oriented" (the value of production center) to "tourist customer orientation" (tourism customer satisfaction theory). Since the beginning of the 21 st century, with the advent of the Internet age and the rapid development of e-commerce, consumers' consumption behavior and consumer psychology have become more diversified and personalized, and it has become more important to focus on tourism customers. Key factors for a company's success include grasping consumer psychology needs, in-depth study of consumer psychology, providing consumers with more diversified services, and establishing a fast-responding travel customer feedback system. It is under this kind of thinking that the theory of tourism customer relationship management has developed rapidly and improved before and after entering the 21 st century.

\section{Concept and development of travel customer service}

The theory of tourism customer relationship management originated from the marketing theory. It was born out of the relationship marketing theory in the theoretical system (in the 1990s), and it was demonstrated and applied in European and American countries, and attracted extensive attention from Western academic circles. However, although many domestic and foreign scholars have done in-depth research on tourism customer relationship management, they have not been consistent with their concepts and implementation. The following table lists some of the domestic 
and foreign scholars' understanding of the definition of tourism customer relationship management in recent years[1].

The connotation of tourism customer relationship management can be recognized from two levels: narrow and broad. From a narrow perspective, tourism customer relationship management is a technology, a solution for enterprises to connect various departments and travel customers, is a combination of modern computer tools and network technology to integrate brands, products, after-sales, travel customers and other factors. As a whole and realize the efficiency optimization of the automatic management system; from a broad perspective, tourism customer relationship management is a strategic idea, the central idea is to establish long-term cooperative relationship with high-quality tourism customers, creating for tourism customers in the production, sales, after-sales and other links Value, the core content is to regard consumers as one of the most important corporate assets, through the purpose of targeted travel customer data analysis, providing targeted and sustainable travel customer service, and enhancing travel customer satisfaction and loyalty, thereby Ensure that both the travel customer value and the corporate profit continue to grow[2].

\section{Based on the value of travel customers in the e-commerce environment}

What is value? From a consumer perspective, the most fundamental understanding of value is the comparison between "paying for costs" and "getting income". Value is one of the important factors affecting purchase behavior or repurchase intention, and is an important reason for influencing and changing consumers' perceptions and ways of thinking. This paper believes that tourism customer value refers to the overall perception and comprehensive evaluation of tourism customers in the process of consumption of products or services, so it is subjective, but when the research object becomes all consumers, the sample is large enough, tourism The attribute of customer value has universality and objectivity (the two are not contradictory), and the value of tourism customer emphasizes the value of the spiritual level of the tourism customer in addition to the material level. Enterprises provide higher value products or services to tourism customers. On the contrary, tourism customers will return to enterprises based on their recognition of enterprises, thus forming a virtuous cycle of economic situation[3].

From the beginning of the 21 st century to today, the development of e-commerce has matured, and the meaning of the value of online travel customers has also undergone fundamental changes. Travel customers who use the network to conduct consumer products or services will also have a comprehensive perception and comprehensive evaluation of them, and will generate actual consumption experience and emotional value. Since most online consumption will still go from online to offline, the value of online travel customers not only reflects the ratio between online consumption and the benefits obtained, but also reflects the end of the traditional channels (packaging, transportation, distribution, etc.). The emotional and experiential value gained during the entire consumption process. At the same time, given the convenience and speed of the network, consumers can quickly feedback through the network and form word of mouth and experience to provide reference for other latecomers, thus bringing more to the enterprise. More traffic and value.

From the above analysis, it is known that the nature of tourism customer value has not changed, whether it is the traditional business model or the network business environment. The change is the carrier, consumption and payment method of commercial operation, and more networks will be added in the perception of consumers. Experience session. In the network environment, the consumer psychology of travel customers has changed, the communication methods between enterprises and travel customers have also changed, and the value of travel customers has been maximized. Therefore, for enterprises, it is necessary to find "pain points" and redesign the whole 
Business processes, enhance the consumer's experience and perception, thus bringing a better reputation and reputation to the enterprise. Over time and the Internet's communication effect, it is transformed into more traffic, and then realized through various flows, ultimately achieving corporate profits. Improvement[4].Customer relationship management model as shown below.

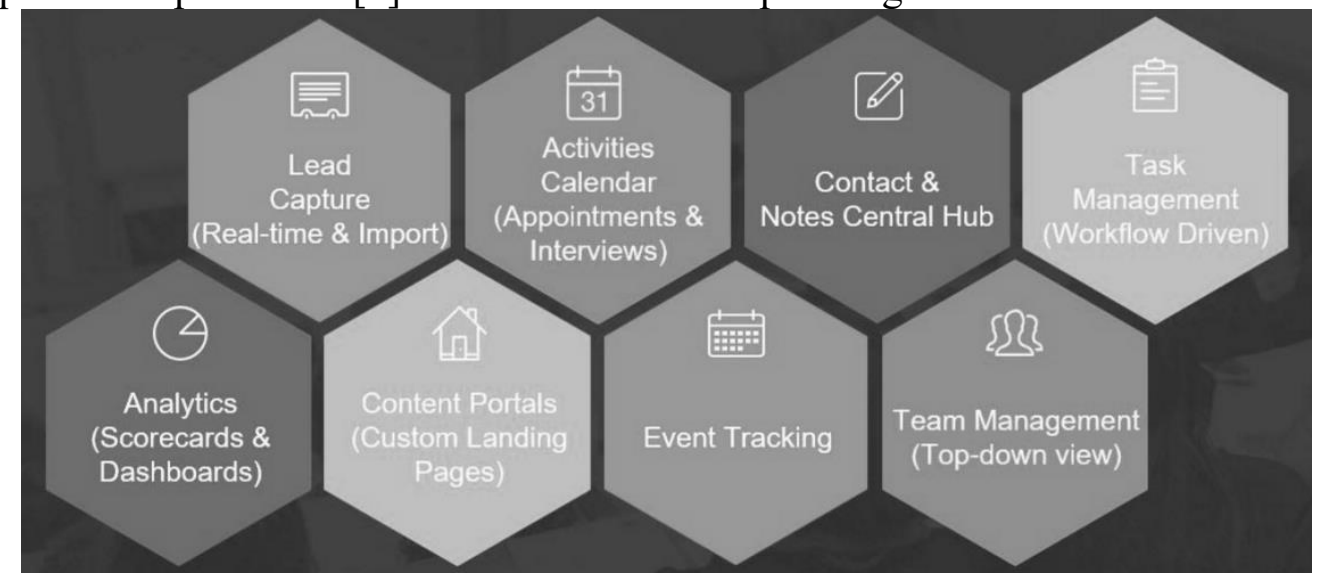

Fig.1 Customer relationship management model

\section{The way to improve the value of travel customer service}

In 1985 Michael Porter proposed the concept of a value chain. Porter believes that "Every business is a collection of activities in the process of designing, producing, selling, sending and assisting its products. All of these activities can be represented by a value chain." We know the value of the company. All the production and operation activities of all departments of the enterprise are closely linked, and the dynamic process of creating value is called the value chain. However, only part of the company's production and operation activities (such as production operations, marketing and travel customer service) can truly create value. Therefore, the value created by the enterprise is actually generated by certain specific links or activities in the value chain. The essence of the enterprise value chain is derived from these business operations that truly create value. The advantages of enterprises in these specific strategic links of the value chain are also the competitive advantages of enterprises. A value-creating organism is formed among various departments within the enterprise. A value chain is also formed between enterprises, enterprises, and groups, and tourism customer relationships are common in internal management and external operations. Therefore, the value creation of tourism customer relationship management is mainly reflected in the enterprise value chain. Through the implementation of tourism customer relationship management, the enterprise value chain is re-established, and the activities in the value chain are value-added[5]. The development trend of customer relationship management is as follows.

From the perspective of CRM, CRM is an idea, a management mechanism, and a software and technology. From a conceptual perspective, CRM is a new management concept. This concept emphasizes people-oriented and regards tourism customers as the core resources of the enterprise. Therefore, the company will highlight the concept of tourism customers as the center in management thinking, corporate culture and system design. Under the guidance of this central idea, we will formulate various corporate strategies and specific implementation plans. From the perspective of management mechanism, CRM is a management mechanism for establishing new relationships between enterprises and tourism customers. It is infiltrated between various departments and employees of enterprises, and requires not only traditional marketing and sales departments but also professional customer service personnel to be tourist customers. Endorsement 
of information, providing more high-quality professional services in the face of travel customers, improving travel customer satisfaction and loyalty, maximizing the balance between travel customer service and sales, and requiring non-tourist customers to contact the department (Finance, logistics, procurement, production, etc.) should also focus on the market, focus on tourism customers, timely and efficient processing of various operating procedures, and improve operational efficiency. From a software and technical perspective, CRM is a complete set of travel customer solutions that apply data mining, data warehousing, big data analytics, modern logistics technology, precision marketing, automated sales and other modern information technologies. The design and implementation of these technologies effectively provide strategic guidance and support for enterprise decision-making. It also provides enterprises with more convenient methods for tourism customer management analysis at the operational level. CRM software is often a module of the enterprise's overall solution. However, the role played far beyond the module itself, not only technically guarantees the normal operation of the CRM system, but also ensures the realization of the CRM concept together with the institutional layer. From the perspective of tourism customer classification, corporate travel customers are divided into internal travel customers (internal employees) and external travel customers (traditional external travel customers). From the perspective of internal travel customers, Jingdong, Ali, SF, Google and other domestic and foreign first-class large enterprises have set a benchmark in internal staff management, not only in the traditional human resources management field, salary compensation, promotion awards, career planning and enterprises.

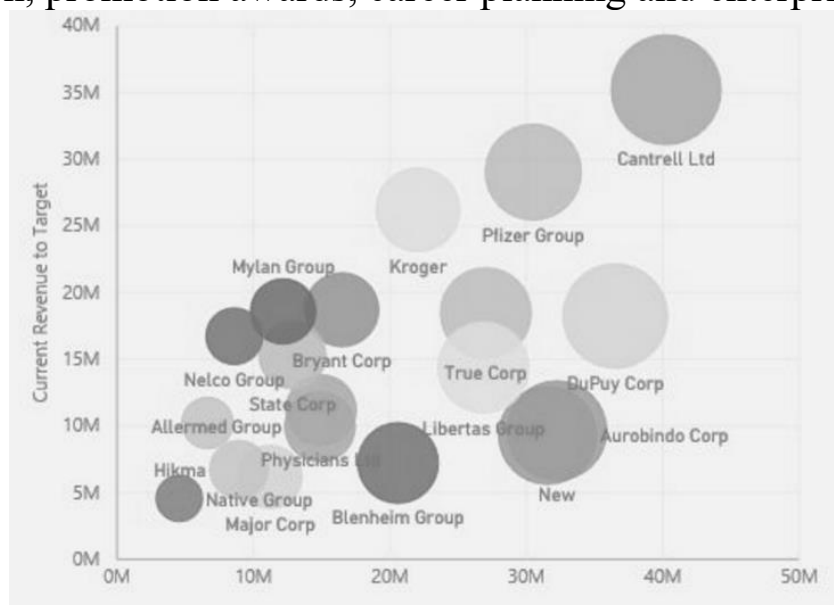

Fig.2 Development trend of customer relationship management

The emphasis of culture is to require enterprises to truly regard employees as family and wealth, to think about what employees think, to solve the actual needs of employees, to abandon a contract and a cold salary, so that employees really feel the company is more Like a big family, it can enhance the sense of belonging of employees, encourage employees to create wealth and value for the company, and realize the realization of self-value.

\section{Summary}

Since the beginning of the 21st century, the business environment of enterprises has undergone dramatic changes, which is due to the rise of e-commerce and the rapid changes in computer network technology. The business philosophy of the company is no longer focused on products, and it is transformed into a tourism customer as the core and a marketing process as the focus. As one of the most important resources of the enterprise, the tourism customer has become an important source of profit for the enterprise, thus strengthening the tourism customer relationship management. The meaning rose to a strategic height. Effective travel customer relationship management activities 
are not only limited to products and services, but also corporate activities that run through the corporate value chain. In the network environment, consumers' consumption trajectories and psychological expectations have certain rules to follow. Enterprises regardless of their size and want to obtain continuous enterprise competitiveness must be designed with consumers as the center and create value for tourism customers.

\section{References}

[1] Manuel Quero,María Belén Ramos, Wilfredo López,Juan José Cubillas,José María González,José Luis Castillo. Uso de customer relationship management para mejorar la atención sanitaria de la ciudadanía. Servicio Salud Andalucía 24 horas. Salud Responde[J]. Gaceta Sanitaria,2016,30(5).

[2] Cristiane Drebes Pedron. Customer Relationship Management e as Pequenas e Médias Empresas: um estudo de múltiplos casos em empresas Portuguesas[J]. REGE - Revista de Gestão,2012,19(2).

[3] Jana Urdziková,Martina Jakábová,Sebastian Saniuk. The Customer Relationship Management in Terms of Business Practice in Slovakia[J]. Research Papers Faculty of Materials Science and Technology Slovak University of Technology,2012,20(Special Nu).

[4] Germinal Isern, Giuseppe Sena. Technical, Organizational and Cross-cultural issues associated with the deployment of Customer Relationship Management (CRM) in Transnational and Global Multicultural Organizations[J]. Journal of Intercultural Management,2015,6(3).

[5] Marcin Kotarba. New factors inducing changes in the retail banking customer relationship management (CRM) and their exploration by the FinTech industry[J]. Foundations of Management,2016,8(1). 